\title{
Fungemia, CTCAE
}

National Cancer Institute

\section{Source}

National Cancer Institute. Fungemia, CT CAE. NCI Thesaurus. Code C143210.

A disorder characterized by the presence of fungus in the blood stream. 